\title{
The relationship between foot posture index, ankle equinus, body mass index and intermetatarsal neuroma
}

\author{
Reza Naraghi ${ }^{1 *}$, Alexandra Bremner $^{2}$, Linda Slack-Smith $^{3}$ and Alan Bryant ${ }^{1}$
}

\begin{abstract}
Background: The main purpose of this study was to investigate the presence of an association between intermetatarsal neuroma and foot type, as measured by the Foot Posture Index. The study also examined whether there was a relationship between foot type and the interspace affected with intermetatarsal neuroma, and whether ankle equinus or body mass index had an effect.

Methods: In total, 100 participants were recruited from The University of Western Australia's Podiatry Clinic, 68 of whom were diagnosed with inter-metatarsal neuroma from 2009 to 2015. There were 32 control participants recruited from 2014 to 2015. The age of subjects was recorded, as were weight and height, which were used to calculate body mass index. The foot posture index and ankle dorsiflexion were measured using standard technique. Independent t-tests and Kruskal-Wallis tests were used to compare differences in foot posture index, body mass index and ankle dorsiflexion between the inter-metatarsal neuroma and control groups. Multivariable logistic regression was also used to model relationships for outcome.
\end{abstract}

Results: The 68 intermetatarsal neuroma subjects had a mean age of 52 years (range 20 to 74 years) and comprised of 56 females and 12 males. The 32 control subjects had a mean age of 49 years (range 24 to 67 years) with 26 females and six males. There were no significant differences between the control and the intermetatarsal neuroma groups with respect to the mean foot posture index scores of the left and right foot $(p=0.21$ and 0.87 , respectively). Additionally no significant differences were detected between the affected intermetatarsal neuroma interspace and foot posture index ( $p=0.27$ and 0.47 , respectively). There was no significant difference in mean body mass index between the intermetatarsal neuroma (26.9 \pm 5.7$)$ and control groups (26.5 \pm 4.1$)(p=0.72)$. There was, however, a significant difference in mean ankle dorsiflexion between the intermetatarsal neuroma and control groups ( $p<0.001$ for both feet). Logistic regression models, adjusted for age, sex, foot posture index and body mass index estimated that the odds of having an intermetatarsal neuroma in the right foot increased by $61 \%$ (OR 1.61; 95\% Cl 1.32-1.96) with each one degree reduction of ankle dorsiflexion, and in the left foot by $43 \%$ (OR 1.43; 95\% Cl 1.22-1.69).

Conclusion: No relationships were found between foot posture index and body mass index with intermetatarsal neuroma, or between foot posture index and the interspaces affected. However, a strong association was demonstrated between the presence of intermetatarsal neuroma and a restriction of ankle dorsiflexion.

Keywords: Neuroma, Equinus deformity, Body mass index

\footnotetext{
* Correspondence: reza.naraghi@uwa.edu.au

${ }^{1}$ School of Surgery, Podiatric Medicine Unit M422, The University of Western

Australia, 35 Stirling Highway, Crawley, WA 6009, Australia

Full list of author information is available at the end of the article
} 


\section{Background}

Intermetatarsal neuroma (IMN), also known as Morton's metatarsalgia is the symptomatic thickening of the plantar intermetatarsal nerve at the level of bifurcation into the digital branches. It is more common in women, and the highest hospital admission rates for surgical removal are for 55-59 year-old males and 50-55 year-old females [1]. People with IMN complain of a sharp burning pain in the interspaces and tingling sensations that may radiate to the toes. This condition commonly affects the third interspace, however, neuromas in the second interspace are also common, while the first and fourth interspaces are rarely involved [2-6].

There are numerous aetiologies speculated in the literature for IMN, such as; pronation $[4,7,8]$, metatarsus proximus [15, 16], trauma [9], ankle equinus [10-14], bursitis $[9,15,16]$, entrapment by the deep transverse metatarsal ligament $[9,17]$, and anatomical variations such as presence of the communicating branch of the lateral plantar nerve [7, 18, 19]. Jarde reported that flatfoot was associated with the development of IMN in $44 \%$ of a 43 patient series [20]. Hagedorn et al., in a 2013 study of 3429 participants, reported associations between foot posture and common foot problems such as hallux abducto valgus, hammertoe, overlapping toe, hallux rigidus and IMN [21]. Their results showed no association between IMN $(N=439)$ and any foot posture and function. However, their study did not compare the foot posture of subjects with foot disorders to that of control subjects.

Excessive pronation can lead to hypermobility of the metatarsal heads, and it has been postulated that movement between the fixed medial column and the more mobile lateral column of the foot can place excessive pressure on the third interspace nerve $[4,7,15,20,22,23]$. This, along with the traction caused by the flexor digitorum brevis has been implicated as a possible cause of the formation of neuroma in the third interspace [4]. It has been suggested that neuroma in the second interspace is more common in the neutral to cavus foot due to the close approximation of the second and third metatarsal heads [24]. This tight space predisposes the nerve to compression by the bursa above the nerve and lumbricalis muscle/tendon arising from the medial aspect of the flexor digitorum longus that runs parallel to the nerve $[25,26]$. Furthermore, the plantar declination of the metatarsals in a cavus foot type can increase pressure over the corresponding nerve [27]. Pazzaglia et al. reported that $75 \%$ of his IMN patients $(n=12)$ in an immunohistochemical study had a cavus foot type with forefoot deformity [6]. There were no case-control studies in the literature that investigated the association of IMN with foot posture. Additionally no proposed mechanism that related foot posture to the occurrence of IMN in the second and third interspaces was identified. This lends us to hypothesize that the occurrence of neuroma in the third interspace would be associated with a pronated foot posture and the occurrence of neuroma in the second interspace would be present in a more neutral to supinated foot type.

To measure the association of foot posture and IMN, investigators can use a simple and efficient tool such as The Foot Posture Index ${ }^{\text {ru }}$ (FPI). FPI is regularly used by clinicians to assess foot type prior to implementing orthotic therapy [28]. The FPI measurement tool has also been validated using Rasch analysis, "which showed that it had good psychometric properties, good individual item fit, and good overall fit of the six criteria to the obtained model" [29]. In addition, Cornwall et al. showed that the FPI had high intra-rater reliability with intraclass correlation coefficient (ICC) levels of greater than 0.9 , however, the inter-rater reliability with ICC values were moderate between 0.525 and 0.655 [30]. Although there is no available literature that has investigated the FPI and IMN, this tool is frequently reported for association of foot type with many other lower extremity conditions [31-33].

Reduced ankle joint dorsiflexion also known as ankle equinus is surmised to cause IMN [10, 13, 14, 34, 35]. A lack of adequate ankle dorsiflexion can result in compensation during gait such as; an early heel lift and an increase in forefoot pressures [11] and thus causing pain in the forefoot [14]. Measurement of ankle joint dorsiflexion is used frequently by clinicians in their day to day practice. There is limited high quality evidence to support the relationship between ankle joint range of motion and IMN, only one case study by Barrett and Jarvis reported an improvement to forefoot nerve symptoms after a gastrocnemius release [35].

This study investigates the association between foot type as measured by the FPI, ankle equinus and body mass index (BMI) and the presence of IMN. This study examines the relationship between foot type and the affected interspace with neuroma.

\section{Methods}

As a case-control study, subjects were recruited from patients attending The University of Western Australia (UWA) Podiatry Clinic. The inclusion criteria for IMN subjects included a minimum of 6-month history of pain in an affected interspace and a clinically demonstrated positive painful Mulder's click and a positive ultrasound confirmatory diagnosis of neuroma in the affected interspace. The inclusion criterion for control subjects was no history of IMN or neuroma-like pain in the forefoot. The exclusion criteria for both neuroma and control groups were a previous history of surgery to the lower extremity, any proximal nerve entrapment at the level of the ankle, knee, hip or back, any history of significant 
trauma to the forefoot area, any difficulty in walking and standing, diabetes or a history of systemic arthritis, bony ankle equinus and any other cause of pain in the forefoot such capsulitis/tenosynovitis or plantar plate pathology.

\section{Recruitment}

Approval was obtained from the University of Western Australia Human Research Ethics Committee for this study, which recruited 100 participants from the UWA Podiatry Clinic, 68 of whom were diagnosed with IMN from 2009 to 2015. There were 32 control participants recruited from 2014 to 2015 . All participants provided a medical history and underwent a physical examination by the corresponding author.

\section{Measurements}

Subjects' ages, weights and heights were recorded, and their BMIs calculated. The FPI was measured according to the FPI User Guide Manual [36] by the corresponding author, who has more than 10 years of experience in clinical practice. Measurements were taken twice and the average value was recorded. Ankle dorsiflexion was measured for each subject with a goniometer using the technique described by Root et al. [37]. The subtalar joint was placed in neutral with the patient in a prone position and the ankle dorsiflexed passively while maintaining subtalar joint neutral position. The subject was then asked to actively dorsiflex the foot while the examiner maintained the subtalar joint in a neutral position. The angle formed between the lateral rear foot and the lateral bisection of the distal $1 / 3$ of the fibula was measured. Two measurements were taken and the average recorded. The intra-rater reliability of the ankle dorsiflexion measurements was tested by using the measurements of eight subjects performed three times to calculate the ICC using a two-way mixed effects model in IBM SPSS Statistics v22 (IBM Corp, Armonk, NY, USA). The ICC of 0.95 (95\% CI 0.83-0.99) indicated that intra-rater reliability was good.

\section{Statistical analysis}

IBM SPSS Statistics v22 was used for analyses. The significance level was set at 0.05 . Results are expressed as mean \pm SD. Medians and ranges are also presented for non-normally distributed measures. Independent sample $t$-tests were used to compare the mean age, BMI, FPI and ankle dorsiflexion between IMN and control groups. In addition, Kruskal-Wallis tests were performed to test for differences in foot type and ankle dorsiflexion between the interspaces affected. Chi-square tests were used to determine whether there was any association between the interspace(s) and the foot (feet) affected in IMN subjects, and whether the proportions of males and females with ankle dorsiflexion of less than $10^{\circ}$ differed.
Associations were also investigated using multivariable logistic regression. Odds ratios (ORs) and 95\% confidence intervals (CIs) are reported.

\section{Results}

The 68 IMN cases had a mean age of $52 \pm 14$ years (range 20 to 74 years) and comprised 56 females and 12 males. The control group of 32 subjects had a mean age of $49 \pm 10$ years (range 24 to 67 years), with 26 females and six males. There were no significant differences in age between the IMN and control groups $(p=0.28)$, or BMI between the IMN $(26.9 \pm 5.7)$ and control $(26.5 \pm 4.1)$ groups $(p=0.72)$. Approximately equal percentages of men and women had IMN: $66.7 \%$ of men and $68.3 \%$ of women $(p=0.89)$.

Figure 1 shows the FPI scores for the IMN and control groups. The mean FPI scores were $3.5 \pm 2.9$ (range -5 to 8 ) for the right-foot IMN and $2.9 \pm 2.8$ (range -1 to 7 ) for the left-foot IMN (Table 1). The control group mean FPI score for the right foot was $2.7 \pm 2.5$ (range -3 to 7 ) and for the left foot, $3.0 \pm 2.9$ (range -5 to 8 ). There were no significant differences in the mean FPI scores for the right and left feet between cases and controls $(p=0.21$ and 0.87 , respectively). There were, however, significant differences in mean ankle dorsiflexion between the IMN and control groups $(P<0.001$ for both feet). The ankle dorsiflexion measurements of IMN subjects were lower by $5.91^{\circ}$ (95\% CI 4.04-7.78) for the right foot, and $7.34^{\circ}$ (95\% CI 5.55-9.13) for the left foot. Figure 2 shows the ankle dorsiflexion measurements of the IMN and control groups. Male and female ankle dorsiflexion measurements did not differ significantly, nor did the proportions of male and female IMN subjects with ankle dorsiflexion less than 10 degrees. They were $87.5 \%$ versus $75.0 \%$ on the right $(p=0.66)$, and $75.0 \%$ versus $86.7 \%$ on the left $(p=0.59)$, for males and females, respectively.

Of the IMN subjects, 28 were diagnosed with neuroma in the second interspace, 23 in the third interspace and 17 in both $2^{\text {nd }}$ and $3^{\text {rd }}$ interspaces. Only three subjects had neuromas in the second and third interspaces of both feet (Table 2). There was no significant association between the interspace(s) affected and the foot (feet) affected with $\operatorname{IMN}(\mathrm{s})(p=0.16)$.

In order to evaluate the relationship between FPI and interspaces affected the IMN subjects were divided according to their affected interspace and compared with controls. The second interspace FPI means on the right $(n=19)$ and left $(n=13)$ were $3.2 \pm 2.6$ and $2.7 \pm 1.9$, respectively. The third interspace FPI means on the right $(n=15)$ and left $(n=11)$ were $3.20 \pm 3.5$ and $2.9 \pm 2.8$, respectively (Table 3 ). FPI did not differ significantly across groups when IMN subjects were divided according to their affected interspace(s) $(p=0.27$ on the right and $p=0.47$ on the left) nor did ankle dorsiflexion 


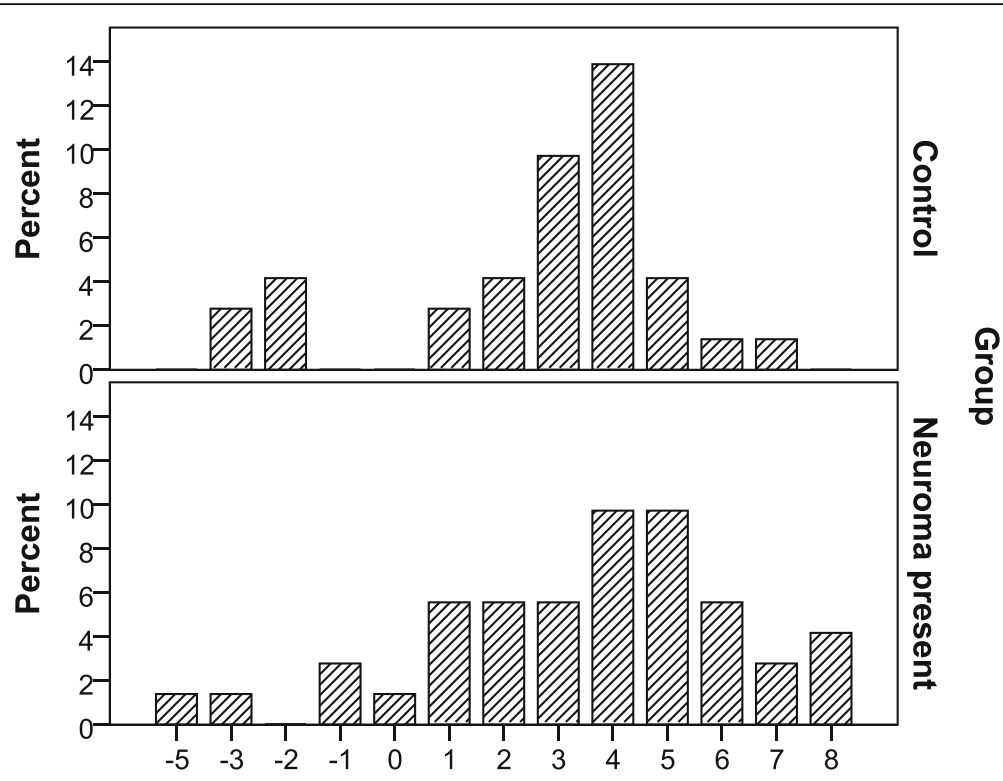

Foot posture index (right)

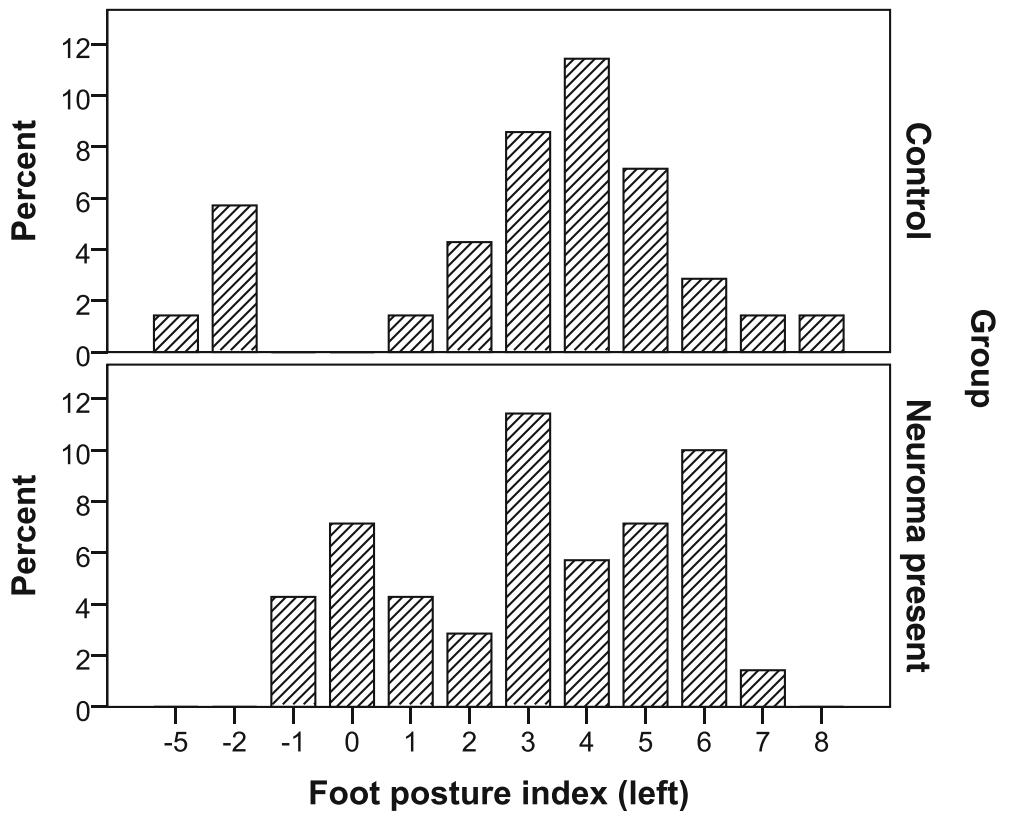

Fig. 1 Graph of foot posture index for intermetatarsal neuroma and control groups - left and right feet

Table 1 Comparison of characteristics between intermetatarsal neuroma and control groups by foot affected

\begin{tabular}{|c|c|c|c|c|c|c|}
\hline & & \multicolumn{2}{|c|}{$\begin{array}{l}\text { Case (IMN present) } \\
n=68\end{array}$} & \multicolumn{2}{|c|}{$\begin{array}{l}\text { Control (No IMN) } \\
n=32\end{array}$} & \multirow[b]{2}{*}{$p$-value } \\
\hline & & Mean \pm SD & Range & Mean \pm SD & Range & \\
\hline \multirow[t]{2}{*}{ IMN right foot $n=40$} & $\mathrm{FPI}$ & $3.5 \pm 2.9$ & -5 to 8 & $2.7 \pm 2.5$ & -3 to 7 & 0.210 \\
\hline & ADF & $5.33 \pm 3.99$ & 0 to 15 & $10.90 \pm 3.62$ & 0 to 20 & $<0.001$ \\
\hline \multirow[t]{2}{*}{ IMN left foot $n=38$} & $\mathrm{FPI}$ & $2.9 \pm 2.8$ & -1 to 7 & $3.0 \pm 2.9$ & -5 to 8 & 0.870 \\
\hline & ADF & $4.10 \pm 3.89$ & 0 to 15 & $11.30 \pm 3.14$ & 2 to 18 & $<0.001$ \\
\hline
\end{tabular}

IMN Intermetatarsal neuroma, FPI Foot Posture Index, ADF Ankle dorsiflexion (degrees)

$P$-values from independent $t$-test comparison of cases with controls. Note there is some overlap in cases as some subjects have IMN in both feet 

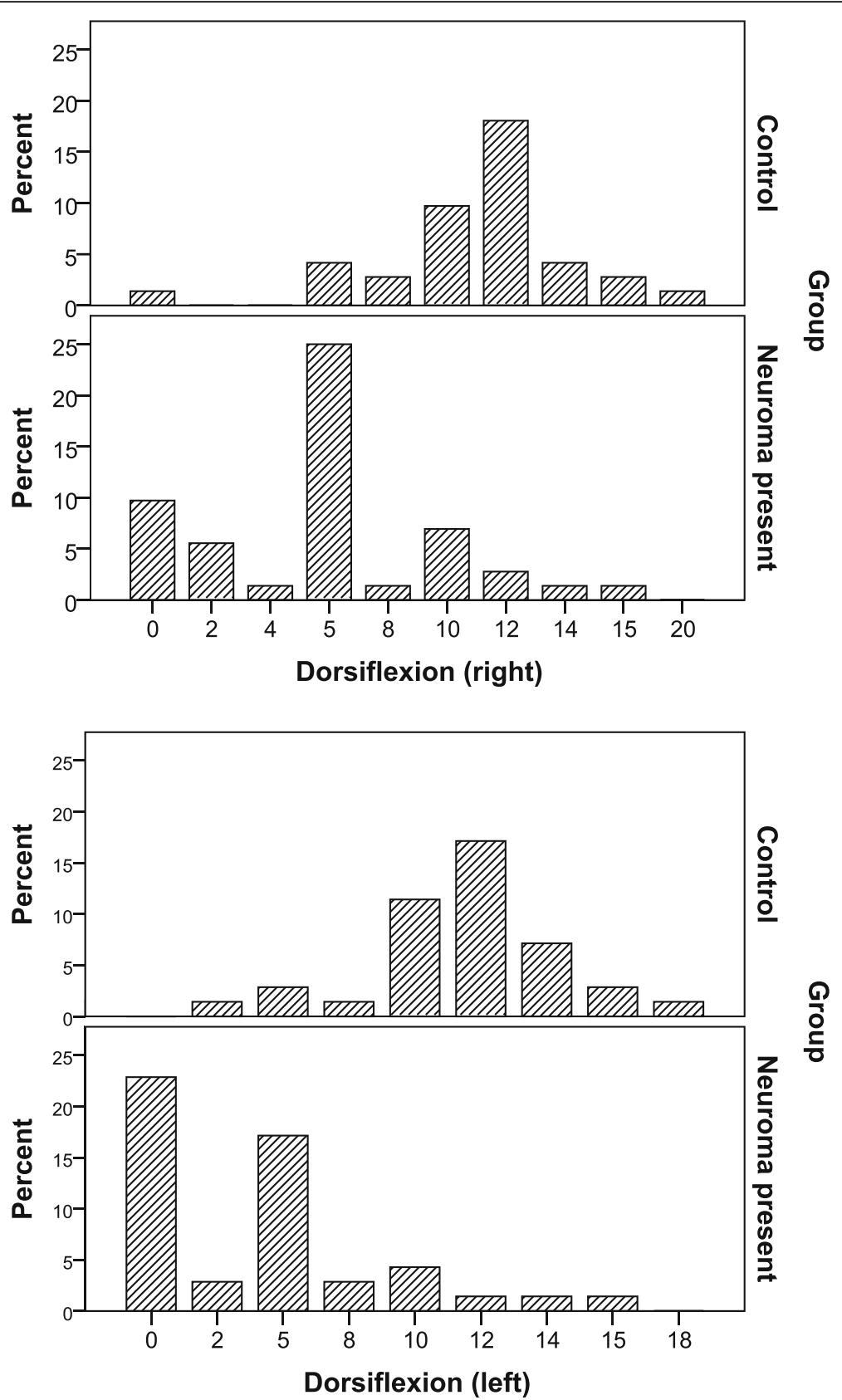

Fig. 2 Graph of ankle dorsiflexion in degrees for intermetatasral neuroma and control groups - left and right feet

Table 2 Description of intermetatarsal neuroma by foot and the interspace(s) affected

\begin{tabular}{lllll}
\hline Interspace & Right foot & Left foot & Both feet & Total \\
\hline $2 / 3$ & 14 & 9 & 5 & $28(41.2 \%)$ \\
$3 / 4$ & 12 & 8 & 3 & $23(33.8 \%)$ \\
Both & 3 & 11 & 3 & $17(25.0 \%)$ \\
Total & $29(42.6 \%)$ & $28(41.2 \%)$ & $11(16.2 \%)$ & 68 \\
\hline
\end{tabular}

Total interspaces affected: right foot $(n=40)$; left foot $(n=38)$ differ across interspace groups $(p=0.80$ on the right and $p=0.79$ ). Logistic regression models, adjusted for age, sex, FPI and BMI, estimated that the odds of having an intermetatarsal neuroma in the right foot decreased by $38 \%$ (OR 0.62; 95\% CI 0.51-0.76) with each additional degree of ankle dorsiflexion, and in the left foot by $30 \%$ (OR 0.70; 95\% CI 0.59-0.82) (Table 4). Alternatively, these odds ratios can be expressed for each degree of reduction in ankle dorsiflexion as 1.61 (95\% CI 1.321.96) for the right foot and 1.43 (95\% CI 1.22-1.69) for the left foot. That is, the odds of having a neuroma increased 
Table 3 The relationship between the affected interspaces and foot posture index and ankle dorsiflexion

\begin{tabular}{|c|c|c|c|c|c|c|}
\hline \multirow[b]{2}{*}{ Interspace } & \multicolumn{3}{|c|}{ Right foot } & \multicolumn{3}{|c|}{ Left foot } \\
\hline & $n$ & $\begin{array}{l}\mathrm{FPI} \\
\text { mean } \pm \mathrm{SD} \\
\text { median (range) }\end{array}$ & $\begin{array}{l}\text { ADF } \\
\text { mean } \pm S D \\
\text { median (range) }\end{array}$ & $n$ & $\begin{array}{l}\mathrm{FPI} \\
\text { mean } \pm \mathrm{SD} \\
\text { median (range) }\end{array}$ & $\begin{array}{l}\mathrm{ADF} \\
\text { mean } \pm \mathrm{SD} \\
\text { median (range) }\end{array}$ \\
\hline $2 / 3$ & 19 & $\begin{array}{l}3.2 \pm 2.6 \\
4(-3 \text { to } 7)\end{array}$ & $\begin{array}{l}4.63 \pm 2.87 \\
5 \text { (0 to } 12)\end{array}$ & 13 & $\begin{array}{l}2.7 \pm 1.9 \\
3(0 \text { to } 5)\end{array}$ & $\begin{array}{l}3.62 \pm 3.84 \\
2(0 \text { to } 10)\end{array}$ \\
\hline $3 / 4$ & 15 & $\begin{array}{l}3.2 \pm 3.5 \\
3(-5 \text { to } 8)\end{array}$ & $\begin{array}{l}5.87 \pm 4.66 \\
5(0 \text { to } 14)\end{array}$ & 11 & $\begin{array}{l}2.9 \pm 2.8 \\
3(-1 \text { to } 7)\end{array}$ & $\begin{array}{l}4.55 \pm 4.25 \\
5(0 \text { to } 12)\end{array}$ \\
\hline Both & 6 & $\begin{array}{l}5.2 \pm 1.7 \\
5 \text { (3 to } 8)\end{array}$ & $\begin{array}{l}6.17 \pm 5.49 \\
5(0 \text { to } 15)\end{array}$ & 14 & $\begin{array}{l}3.6 \pm 2.5 \\
4(-1 \text { to } 6)\end{array}$ & $\begin{array}{l}3.86 \pm 5.10 \\
2.5(0 \text { to } 15)\end{array}$ \\
\hline$p$-value & & 0.27 & 0.80 & & 0.47 & 0.79 \\
\hline
\end{tabular}

$p$-value from Kruskal-Wallis one way analysis of variance test (non-parametric test)

by 61 and $43 \%$ for the right and left feet, respectively, with each degree of reduction in ankle dorsiflexion.

In summary, there were no significant differences in FPI between IMN interspaces affected or between cases and controls. The IMN subjects had a significant decrease in ankle dorsiflexion measurements compared with control subjects.

\section{Discussion}

This study used the FPI to investigate for an association between foot posture and IMN. The results showed no association between foot posture and IMN formation. Our mean FPI values were slightly less than the normative value of +4 reported by Redmond et al., who measured FPI on 619 healthy subjects [38]. The mean FPI scores in our study were $3.5 \pm 2.9$ (range -5 to 8 ) for the right-foot IMN and $2.9 \pm 2.8$ (range -1 to 7 ) for the leftfoot IMN which based on our sample size is not significantly different to our controls $(p=0.21$ and $p=0.87$ respectively). Hagedorn et al. also in the Framingham population study did not find any association between foot posture and IMN [21].

Most of the literature states that the third interspace is more commonly affected with IMN for anatomical and biomechanical reasons $[4,6,9,25,39]$. Keh et al. [40]

Table 4 Multivariable logistic regression estimates of odds of one or two intermetatarsal neuromas

\begin{tabular}{lllllll}
\hline \multirow{2}{*}{ Variable } & \multicolumn{1}{l}{ Right foot } & & & Left foot & \\
\cline { 2 - 3 } \cline { 6 - 7 } & OR $(95 \% \mathrm{Cl})$ & $p$-value & & OR $(95 \% \mathrm{Cl})$ & $p$-value \\
\hline Age (years) & $1.06(0.99,1.14)$ & 0.75 & & $0.99(0.94,1.04)$ & 0.75 \\
BMl (kg/m2) & $0.88(0.73,1.06)$ & 0.20 & & $1.09(0.96,1.24)$ & 0.20 \\
Female $^{a}$ & $2.08(0.34,12.8)$ & 0.95 & & $0.96(0.23,4.03)$ & 0.95 \\
FPI & $1.29(0.93,1.81)$ & 0.85 & & $1.02(0.82,1.27)$ & 0.85 \\
ADF (degrees) & $0.62(0.51,0.76)$ & $<0.001$ & & $0.70(0.59,0.82)$ & $<0.001$ \\
\hline
\end{tabular}

$B M I$ Body mass index FPI Foot Posture index

$A D F$ Ankle dorsiflexion (degrees)

$O R$ Odds ratio, $\mathrm{Cl}$ Confidence interval

${ }^{a}$ Compared to male. Other ORs are per unit increase reported a slightly increased occurrence of neuroma in the second interspace, but an equal distribution of neuroma in both interspaces was reported by Mann et al. [5] In this study approximately $41 \%$ occurred in the second interspace only, $34 \%$ in the third interspace only and $25 \%$ in both interspaces (Table 3). We did not find any relationship between FPI and IMN in a particular interspace. Therefore, the belief that IMN would more commonly occur in the third interspace in a more pronated foot as a result of hypermobility of the lateral column relative to the medial column cannot be supported by these findings. Furthermore, even though the second interspace was the most frequently affected site, cavus foot posture was not associated with formation of IMN in the second interspace.

It is reasonable to assume that individuals with a high BMI would have increased pressure in the forefoot during the propulsive phase of gait, which may traumatize plantar interspace nerves. However, in our study, there was no significant difference in mean BMI between IMN and control groups. The Johnston County study reported that there was no clear association between BMI and the presence of foot deformities [41]. However, in a systematic review by Butterworth et al., a significant association between foot pain as a result of non-specific foot disorders and increasing BMI was reported [42]. While obesity has been linked to an increase in plantar pressure measurements [43], which can lead to a more pronated foot and increase in foot pain [44, 45], in our casecontrol series no relationship between BMI and IMN formation was established.

A number of authors state that a lack of ankle dorsiflexion in gait increases pressure of the forefoot $[10,11,34,35,46]$. Barrett went as far as to recommend endoscopic gastrocnemius release as a treatment for IMN patients exhibiting ankle equinus [35]. DiGiovanni et al. studied the effect of isolated gastrocnemius tightness in a group of 34 patients with forefoot and midfoot pain versus a control group of 34 without any foot or ankle pain. In his study he used 
an equinometer to measure ankle dorsiflexion and defined equinus as less than $5^{\circ}$, and found that in the patient group, there was a twofold higher rate of equinus compared to the control group. The study, however, did not have any patients with IMN and only seven subjects were diagnosed with metatarsalgia of non-neurological origin. Although the measurement technique used in our study has been reported in the literature as unreliable [47, 48] the intra-rater reliability was found to be high.

One limitation of this study was that FPI is a static measurement and may not represent a subject's dynamic function during gait given that IMN symptoms occur mostly during the propulsive phase of gait. However, some studies support the use of FPI as a valid tool in predicting dynamic function of the foot during gait $[49,50]$. Secondly, gender imbalance may have affected the results, as $82 \%$ of the study subjects were female. However, there were no significant differences in mean ankle dorsiflexion measurements between male and female subjects. Presentation of IMN is more commonly seen in women, and their rate of hospital admission is three times higher that of males in Australia [1].

\section{Conclusion}

This study examined the relationship of FPI, BMI and ankle dorsiflexion with IMN and to the author's best knowledge is the only case-control study of this type in the literature. No relationship was found between foot type, BMI or IMN; nor was there an association between the FPI and the interspaces affected by IMN. However, there was a strong association between the presence of IMN and a restriction of ankle dorsiflexion. The authors suggest that future studies investigate the effect of the management of ankle equinus on IMN treatment.

\section{Acknowledgments}

The authors acknowledge Dr Renee Silvester for reviewing and commenting on the manuscript.

\section{Funding}

There are no sources of funding reported for this project.

\section{Availability of data and materials}

All data has been kept in a locked cabinet within the Podiatric Medicine Unit/ University of Western Australia. The author can be contacted directly should there be any need to access the data if required.

\section{Authors' contributions}

RN with guidance of $A B$ and LS-S wrote the study protocol. RN designed the data collection forms, performed data collection and drafted the manuscript. $\mathrm{RN}$ and ABre conducted the statistical analysis. All authors were involved with interpretation of data and critical revision of the manuscript. All authors read and approved the final manuscript.

\section{Consent for publication}

Consent was obtained from participants with regards to publishing the results of the study in a scientific journal and also to present these at conferences and meetings.

\section{Ethics approval and consent to participate}

Ethics approval was obtained by the University of Western Australia's human ethics committee (project number RA/4/1/2543). All subjects were given patient information and gave written informed consent for taking part in the study.

\section{Author details}

${ }^{1}$ School of Surgery, Podiatric Medicine Unit M422, The University of Western Australia, 35 Stirling Highway, Crawley, WA 6009, Australia. ${ }^{2}$ School of Population Health M431, The University of Western Australia, 35 Stirling Highway, Crawley, WA 6009, Australia. ${ }^{3}$ School of Dentistry M512, The University of Western Australia, 35 Stirling Highway, Crawley, WA 6009, Australia.

Received: 20 April 2016 Accepted: 25 November 2016

Published online: 01 December 2016

\section{References}

1. Naraghi R, Bryant A, Slack-Smith L. Description of total population hospital admissions for Morton's metatarsalgia in Australia. J Am Podiatr Med Assoc. 2014;104(5):451-4

2. Kim J, Choi J, Park J, Wang J. An anatomical study of Morton's interdigital neuroma: the relationship between the occuring site and the deep transverse metatarsal ligament (DTML). Foot Ankle Int. 2007;28(9):1007-10.

3. Jacobson TJ, Craig TJ, van Holsbeeck TM, Quinn TT. Sonography of Morton's neuromas. AJR Am J Roentgenol. 2000;174(6):1723-8.

4. Wu K. Morton's interdigital neuroma: a clinical review of its etiology, treatment, and results. J Foot Ankle Surg. 1996;35(2):112-9.

5. Mann RA, Reynolds JC. Interdigital Neuroma-A Critical Clinical Analysis. Foot Ankle Int. 1983;3(4):238-43.

6. Pazzaglia U, Moalli S, Leutner M, Gera R. Morton's neuroma: an immunohistochemical study. The Foot. 1996;6(2):63-5.

7. Amis JA, Silverhus SW, Liwnicz BH. An anatomical basis for recurrence after Morton's Neuroma excision. Foot Ankle. 1992:13:153-6.

8. Graham CE, Graham DM. Morton's Neuroma: A Microscopic Evaluation. Foot Ankle Int. 1984;5(3):150-3.

9. Hassouna H, Singh D. Morton's metatarsalgia: pathogenesis, aetiology and current management. Acta Orthop Belg. 2005;71(6):646.

10. Hill RS. Ankle equinus. Prevalence and linkage to common foot pathology. J Am Podiatr Med Assoc. 1995;85(6):295-300.

11. Johnsone $\mathrm{CH}$, Christensen JC. Biomechanics of the first ray part $\mathrm{V}$ : The effect of equinus deformity: A 3-dimensional kinematic study on a cadaver model. J Foot Ankle Surg. 2005;44(2):114.

12. Orendurff M, Rohr E, Sangeorzan B, Weaver K, Czerniecki J. An equinus deformity of the ankle accounts for only a small amount of the increased forefoot plantar pressure in patients with diabetes. J Bone Joint Surg. 2006;88(1):65-8.

13. Digiovanni C, Kuo R, Tejwani N, Price R. Isolated gastrocnemius tightness. J Bone Joint Surg. 2002;84(6):962-70.

14. Perez HR. Equinus deformity as a factor in forefoot nerve entrapment. J Am Podiatr Med Assoc. 2007;97(2):171.

15. Jain S, Mannan K. The Diagnosis and Management of Morton's Neuroma: A Literature Review. Foot \& Ankle Specialist. 2013;6(4):307-17.

16. Bossley CJ, Cairney PC. The intermetatarsophalangeal bursa-its significance in Morton's metatarsalgia. J Bone Joint Surg Br. 1980;62-B(2):184.

17. Gauthier G. Thomas Morton's disease: a nerve entrapment syndrome. A new surgical technique. Clin Orthop Relat Res. 1979;142:90-2.

18. Bakkum BW, Darby SA, Frank PW. The communicating branch of the lateral plantar nerve: A descriptive anatomic study. Clin Anat. 1996;9(4):237-43.

19. Bilge O, Ozer MA, Govsa F. Anatomical study of the communicating branches between the medial and lateral plantar nerves. Surg Radiol Anat. 2005;27(5):377-81

20. Jarde O. Morton's metatarsalgia. Foot Ankle Surg. 1998:4(4):187-91.

21. Hagedorn TJ, Dufour AB, Riskowski JL, Hillstrom HJ, Menz HB, Casey VA, et al. Foot Disorders, Foot Posture, and Foot Function: The Framingham Foot Study. PLoS One. 2013;1-7. 
22. Root ML, Orien WP, Weed JH, Hughes RJ. Clinical Biomechanics: Normal and abnormal function of the foot. 1st ed. Los Angeles, California: Clinical biomechanics corporation; 1977

23. Konstantine B. The Treatment of Morton's Neuroma, a Significant Cause of Metatarsalgia for People Who Exercise. Int J Clin Med. 2013;04(01):19-24.

24. Bygrave CJ, Jones S, Smith TW, Flowers MJ, Betts RP. Ultrasonic diagnosis of Morton's neuroma: a guide to problems, pointers, pitfalls and prognosis. The Foot. 2003;13(2):92-9.

25. Guerin G. Metatarsus proximus: Another etiology for Morton's neuroma. The Journal of Current Podiatric Medicine. 1988;9:20.

26. Sunshein K, Jones R, Harkless L, Grace TS. Metatarsus proximus and digital divergence. Association with intermetatarsal neuromas. J Am Podiatr Med Assoc. 1993;83(7):406-11.

27. Abassian A, Pomeroy G. The idiopathic cavus foot-Not so subtle after all. Foot Ankle Clin N America. 2013;18:629-42.

28. Copper AW, Scharfbillig RW, Scutter SD, Williams MT, Evans AM. Reliability of the foot posture index and traditional measures of foot position. J Am Podiatr Med Assoc. 2003;93(3):203-13

29. Keenan AM, Redmond AC, Horton M, Conaghan PG, Tennant A. The Foot Posture Index: Rasch analysis of a novel, foot-specific outcome measure. Arch Phys Med Rehabil. 2007;88-93.

30. Cornwall MW, McPoil TG, Lebec M, Vicenzino B, Wilson J. Reliability of the Modified Foot Posture Index. J Am Podiatr Med Assoc. 2008;98(1):7-13.

31. Barton CJ, Levinger P, Crossley KM, Webster KE, Menz HB. Relationships between the Foot Posture Index and foot kinematics during gait in individuals with and without patellofemoral pain syndrome. (Research)(Report). J Foot Ankle Res. 2011;4:10

32. Levinger $P$, Menz HB, Fotoohabadi MR, Feller JA, Bartlett JR, Bergman NR. Foot posture in people with medial compartment knee osteoarthritis. J Foot Ankle Res. 2010;3(1):1-8

33. Abourazzak F, Kadi N, Azzouzi H, Lazrak F, Najdi A, Nejjari C, et al. A positive association between foot posture index and medial compartment knee osteoarthritis in moroccan people. The open rheumatology journal. 2014:8:96.

34. Shearstone J, Guillano M, Dananberg HJ. Manipulation method for the treatment of ankle equinus. J Am Podiatr Med Assoc. 2000:90(8):385-9.

35. Barrett SL, Jarvis J. Equinus deformity as a factor in forefoot nerve entrapment: treatment with endoscopic gastrocnemius recession. J Am Podiatr Med Assoc. 2005;95(5):464-8.

36. Redmond A. The Foot Posture Index, Six Item version FPI-6. User Guide and Manual. Leeds UK: University of Leeds; 2005.

37. Root ML, Orien WP, Weed JH, Hughes RJ. Biomechanical examination of the foot Los Angeles Clinical Biomechanics Corp; 1971. $136 \mathrm{p}$

38. Redmond A, Crane $Y$, Menz H. Normative values for the Foot Posture Index. J Foot Ankle Res. 2008;1(1):6.

39. Rusin JJ, Tate RO. Morton's neuroma: its ultrastructural anatomy and biomechanical etiology. J Am Podiatr Med Assoc. 1978;68(12):797-807.

40. Keh RA, Ballew KK, Higgins KR, Odom R, Harkless LB. Long-term follow-up of Morton's neuroma. J Foot Surg. 1992;3:93-5.

41. Golightly YM, Hannan MT, Dufour AB, Hillstrom HJ, Jordan JM. Foot Disorders Associated With Overpronated and Oversupinated Foot Function: The Johnston County Osteoarthritis Project. Foot Ankle Int. 2014;35(11):1159-65.

42. Butterworth PA, Landorf KB, Smith SE, Menz HB. The association between body mass index and musculoskeletal foot disorders: a systematic review. Obes Rev. 2012;13(7):630-42

43. Hills AP, Hennig EM, McDonald M, Bar-Or O. Plantar pressure differences between obese and non-obese adults: a biomechanical analysis. Int J Obes Relat Metab Disord. 2001;25(11):1674.

44. Menz HB. Biomechanics of the Ageing Foot and Ankle: A Mini-Review. Gerontology. 2015:61(4):381-8

45. Monteiro M, Gabriel R, Aranha J, Castro MNE, Sousa M, Moreira M. Influence of obesity and sarcopenic obesity on plantar pressure of postmenopausal women. Clinical Biomechanics. 2010;25(5):461-7.

46. Van Gils C, Roeder B. The effect of ankle equinus upon the diabetic foot Clin Podiatr Med Surg. 2002;19(3):391.

47. Gatt A, Chockalingam N. Clinical assessment of ankle joint dorsiflexion: a review of measurement techniques. J Am Podiatr Med Assoc. 2011;101(1):59-69.

48. Gatt A, Chockalingam N. Validity and reliability of a new ankle dorsiflexion measurement device. Prosthet Orthot Int. 2013;37(4):289-97.
49. Chuter VH. Relationships between foot type and dynamic rearfoot frontal plane motion. J Foot Ankle Res. 2010;3(9):9.

50. Teyhen DS, Stoltenberg BE, Eckard TG, Doyle PM, Boland DM, Feldtmann JJ, et al. Static foot posture associated with dynamic plantar pressure parameters. J Orthop Sports Phys Ther. 2011;41(2):100.

\section{Submit your next manuscript to BioMed Central and we will help you at every step:}

- We accept pre-submission inquiries

- Our selector tool helps you to find the most relevant journal

- We provide round the clock customer support

- Convenient online submission

- Thorough peer review

- Inclusion in PubMed and all major indexing services

- Maximum visibility for your research

Submit your manuscript at www.biomedcentral.com/submit
) Biomed Central 